\title{
Article
}

\section{Anionic Host Defence Peptides from the Plant Kingdom: Their Anticancer Activity and Mechanisms of Action}

Harris, Frederick, Prabhu, Saurabh, Dennison, Sarah Rachel, Snape, Timothy James, Lea, Robert William, Mura, Manuela and Phoenix, David Andrew

Available at http://clok.uclan.ac.uk/15102/

Harris, Frederick, Prabhu, Saurabh, Dennison, Sarah Rachel ORCID: 00000003-4863-9607, Snape, Timothy James ORCID: 0000-0003-2766-4491, Lea, Robert William, Mura, Manuela and Phoenix, David Andrew (2016) Anionic Host Defence Peptides from the Plant Kingdom: Their Anticancer Activity and Mechanisms of Action. Protein and Peptide Letters, 23 (8). pp. 676-687. ISSN 0929-8665

It is advisable to refer to the publisher's version if you intend to cite from the work. http://dx.doi.org/10.2174/0929866523666160511151215

For more information about UCLan's research in this area go to http://www.uclan.ac.uk/researchgroups/ and search for <name of research Group>.

For information about Research generally at UCLan please go to http://www.uclan.ac.uk/research/

All outputs in CLoK are protected by Intellectual Property Rights law, including Copyright law. Copyright, IPR and Moral Rights for the works on this site are retained by the individual authors and/or other copyright owners. Terms and conditions for use of this material are defined in the policies page. 


\section{Anionic Host Defence Peptides from the Plant Kingdom: Their Anticancer Activity and Mechanisms of Action}

Frederick Harris ${ }^{1}$, Saurabh Prabhu ${ }^{2}$, Sarah R. Dennison², Timothy J. Snape², Robert Lea², Manuela Mura ${ }^{3}$ and David A. Phoenix ${ }^{4 *}$

${ }^{1}$ School of Forensic and Investigative Science, University of Central Lancashire Preston, PR1 2HE, UK

${ }^{2}$ School of Pharmacy and Biomedical Sciences, University of Central Lancashire Preston, PR1 2HE, UK

${ }^{3}$ School of Computing Engineering and Physical Science, University of Central Lancashire, Preston, PR1 2HE, UK.

${ }^{4}$ Vice Chancellor, London South Bank University, London SE1 0AA.

*Author for correspondence: Professor D. A. Phoenix, Tel: +44 (0) 207815 6001, Fax: +44 (0) 207815 6099, E-mail: phoenixd@lsbu.ac.uk

\section{Abstract}


It is becoming increasingly clear that plants, ranging from across the plant kingdom produce anionic host defence peptides (AHDPs) with potent activity against a wide variety of human cancers cells. In general, this activity involves membrane partitioning by AHDPs, which leads to membranolysis and / or internalization to attack intracellular targets such as DNA. Several models have been proposed to describe these events including: the toroidal pore and Shai-Matsuzaki-Huang mechanisms but, in general, the mechanisms underpinning the membrane interactions and anticancer activity of these peptides are poorly understood. Plant AHDPs with anticancer activity can be conveniently discussed with reference to two groups: cyclotides, which possess cyclic molecules stabilized by cysteine knot motifs, and other ADHPs that adopt extended and $\alpha$-helical conformations. Here, we review research into the anticancer action of these two groups of peptides along with current understanding of the mechanisms underpinning this action. 


\section{Introduction}

How plants protected themselves from microbial infections was long an enigma, given that they lack an adaptive immune system, which mediates the defence of humans and other vertebrates against these infections [1]. It is now known that to offset the lack of specialized mobile immune cells possessed by vertebrates, every cell in a plant has the facility to launch an effective immune response, which is mediated by a multi-layered innate immune system that comprises self-surveillance, systemic signalling and chromosomal changes acting in combination to protect against microbial infection and other threats [2, 3]. One layer of this immune response involves the production of an arsenal of defence peptides and proteins, which includes: pathogenesis-related (PR)-proteins [4-7], recently redefined as 'inducible defencerelated proteins $[8,9]$, and host defence peptides (HDPs), whose primary role is a front-line response to microbial infections [10-13]. On a structural basis, these HDPs can be grouped into the major families: defensins, cyclotides, 2S albumins, lipid transfer proteins, hevein-like proteins knotins, snakins, and glycine-rich proteins [14-21]. Most of these peptides are cationic (CHPDs), which facilitates their toxicity to target cells [10-21], but it is becoming increasingly clear that plants also produce a number of anionic HDPs (AHDPs) with toxicity to pests, fungi, viruses, bacteria and cancer cells [13, 22-28]. Currently, the structural / functional relationships underpinning the anticancer and other biological activities of plant AHDPs are poorly understood although, in most cases, the molecular architecture of these peptides has been elucidated [13, 22, 23, 27, 28]. Based on their structural characteristics, plant AHDPs with anticancer activity can be divided into two groups: cyclotides, which possess cyclic molecules stabilized by cysteine knot motifs, and other ADHPs that adopt extended and $\alpha$-helical conformations [22]. Here, we review research into the anticancer action of these two groups of 
peptides along with current understanding of the mechanisms underpinning this action and discus their potential to serve as agents in the fight against cancers.

\section{AHDPs that adopt $\alpha$-helical and extended conformations}

It has previously been shown that HDPs were present in leaf extracts of Cycas revoluta from the Cycadaceae family [29] and more recently, Cr-ACP1 (net charge -1), was identified in seeds of the plant (Table 1) [30]. The peptide was found to have selective toxicity towards human cells from colon carcinoma (HCT15) and epidermoid cancer (Hp2) with $\mathrm{IC}_{50}$ values that were $1.5 \mathrm{mM}$ and $0.6 \mathrm{mM}$ respectively. These results suggested that $\mathrm{Cr}$-ACP1 functioned as a weak anticancer agent and mechanisms underpinning the action of the peptide against the HCT15 and Hp2 cell lines were investigated. It appeared that these mechanisms involved intracellular targets, requiring $\mathrm{Cr}$-ACP1 to translocate across the membranes of target cancer cells. Consistent with this observation, studies on the antibacterial activity of the peptide suggested that the positive charge carried by its sole lysine residue and overall charge distribution played a role in facilitating membrane interaction by the peptide. Reinforcing this suggestion, theoretical analysis of the peptide showed that it had the potential to adopt $\alpha$-helical structure with a high level of amphiphilicity, indicative of an ability to interact with membranes [31, 32]. This molecular architecture is adopted by many other AMPs [13, 24, 25] and in particular, buforin IIb, which is an $\alpha$-helical CAMP that crosses target membranes to bind DNA and thereby promote anticancer action via the induction of apoptosis [33]. Cr-ACP1 showed similarities to the anticancer action of buforin IIb and was found to have a strong affinity for DNA, which appeared to involve the ability of its charged and polar residues to form a stable hydrogen bond network with DNA nucleotides (Figure 1). Further studies on Cr-ACP1 led to the suggestion that the anticancer action of the peptide utilised anti-proliferative mechanisms 
involving the binding of Cr-ACP1 to DNA, thereby inducing cell cycle arrest in the G0-G1 phase and the initiation of apoptotic mechanisms of cell death [30].

Cn-AMP2 (net charge -1) is an antibacterial peptide that was first identified in green coconut water, which is the clear liquid inside young coconuts from Cocos nucifera of the Arecaceae and a popular drink in Tropical Asia and Latin America (Table 1) [34]. In a more recent study, Cn-AMP2 was shown to have selective toxicity towards cancer cells from human glioma cell lines (1321N1 and U87MG) with $\mathrm{IC}_{50}$ values of $1.25 \mathrm{mM}$ and $1.85 \mathrm{mM}$ respectively [35]. Further studies on the peptide lead to the suggestion that, similarly to $\mathrm{Cr}$ ACP1, Cn-AMP2 functioned as a weak anticancer agent, which utilised anti-proliferative mechanisms via translocation across the membrane to employ intracellular sites of action [22, 36, 37]. Strongly supporting this suggestion, Cn-AMP2 demonstrated no membranolytic ability towards any of the cells lines studied as can be seen from Figure 2, which clearly shows that cells treated with the peptide exhibited no significant morphological differences to control cells; no evidence of cell-death, as indicated by a round morphology; and no sign of cell lysis, as witnessed by membrane fragmentation or the presence of cellular debris (Figure 2). In combination, these data suggested that $C n$-AMP2 may be cytostatic towards the $1321 \mathrm{~N} 1$ and U87MG cell lines and, although the targets of their anti-proliferative mechanism were not investigated, it was speculated that these mechanisms may involve DNA-binding [35].

The ability of Cn-AMP2 to interact with cancer cell membranes was investigated and it was shown that in the presence of lipid mimics of cancer cell membranes, the peptide adopted an extended conformation. In this conformation, Cn-AMP2 exhibited a strongly hydrophobic region, formed by the C-terminal eight residues of the peptide, YFVFSVGM, which was flanked by a short anionic segment, TES [36, 37]. This residue arrangement endows Cn-AMP2 
with primary amphiphilicity [36, 37], which has been reported for other anticancer peptides such as indolicidin $[38,39]$ and is known to mediate the ability of these peptides to traverse membranes [40]. By analogy to indolicidin, it was suggested that the ability of Cn-AMP2 to traverse cancer cell membranes may be hydrophobicity driven by a mechanism, involving the peptide’s C-terminal region [36, 37]. Most recently, molecular dynamic simulations were undertaken, which strongly supported these suggestions and showed that Cn-AMP2 was able to translocate phospholipid assemblies that mimicked cancer cell membranes (Figure 3). These MD simulations are depicted in Figure 3, which shows that the extended form of Cn-AMP2 is able to approach the surface of a target membrane (Figure 3A) and insert into this membrane (Figure 3B). This insertion event is mediated by the association of the peptide's anionic Nterminal 'TES' segment with cationic moieties in the membrane head-group region, such as the choline group of DMPC. These electrostatic interactions are complemented by penetration of the hydrophobic C-terminal 'YFVFSVGM' segment of Cn-AMP2 into the apolar acyl chain region of the membrane (Figure 3B). Led by its N-terminal segment, the peptide then crosses this acyl chain region (Figure 3C) and exits through the opposing membrane leaflet (Figure 3D) accompanied by no significant overall perturbation of the bilayer (Figures 3A to 3D). It was proposed that $C n$-AMP2 uses a similar mechanism to enter the human glioma cell lines, 1321N1 and U87MG, whereupon the internalized peptide attacks intracellular targets, such as DNA, thereby inhibiting the proliferation and inducing the death of these cells (Figure 3E) [36, 37].

\section{AHDPs from cyclotides}

A number of AHDPs have been identified within the cyclotides, which are a major family of cyclic HDPs [41-43] with anticancer action (Table 2) and a range of other biological 
Published Harris F, et al 2016 Protein Pept Lett. 2016 May 11. [Epub ahead of print] PMID: 27165406

activities [41-43], which is generally based on the ability of these peptides to interact with target cell membranes [22, 23, 27]. These peptides are listed in various databases and are now known to be ubiquitous in plants $[13,24,25,44-46]$ with most identified in the Rubiaceae, Violaceae [47, 48] and Fabaceae families [49-52] (Table 1) whilst others have been recently reported in the Cucurbitaceae [48, 53], Solanaceae [54], Poaceae [55] and Apocynaceae families [47]. Kalata B2 (net charge -1) is generally taken as the prototypic member of AHDPs in cylotides [23, 27] and was first reported in the early 1970s when it was identified in Oldenlandia affinis of the Rubiaceae (Table 1), which is widely dispersed over tropical Africa and is also found in tropical Asia [56-58]. The peptide derives its name from the fact that it is a component of the uterotonic agent in a medicinal preparation, kalata-kalata [58, 59], which is derived from O. affinis and is used in parts of Africa to accelerate child birth [60,61]. Several recent studies reported that kalata B2, along with kalata B13 (net charge -2; Tables 1 and 2), which is also derived from O. affinis, possessed potent anticancer activity. It was found that both peptides exhibited $\mathrm{IC}_{50}$ values that were $\leq 5.0 \mu \mathrm{M}$ when directed against cell lines of lymphoma (U-937 GTB) colorectal cancer (Ht116) and colonadeno carcinoma (HT29) that were generally comparable to that of doxorubicin $[62,63]$, a well-established anticancer drug [64]. Other AHDPs from plants of the Rubiaceae, include palicourein (net charge -1), from the tropical plant, Palicourea condensate [65], and chaC1 (net charge -1), which was recently discovered in Chassalia chartacea [66]. These peptides were found to have potent activity against cell lines of cervical cancer (HeLa) and acute lymphoblastic leukaemia (CEM-SS) with IC $_{50}$ values of $1.5 \mu \mathrm{M}$ and $9.8 \mu \mathrm{M}$, respectively [66, 67].

Several ADHPs with anticancer activity, named cliotides CT2 and CT3 (net charges of -1), were recently reported in the tropical plant, Clitoria ternatea, of the Fabaceae family (Table 1), and were shown to be effective against HeLa cells ( IC $_{50}=0.6 \mu \mathrm{M}$ and $8.0 \mu \mathrm{M}$ 
respectively) [50]. More recently, cliotide CT2 was found to have activity against human nonsmall lung cancer cells (A549; $\mathrm{IC}_{50}=7.6 \mu \mathrm{M}$ ) and an A549-derived paclitaxel-resistant subline (A549/taxol; $\mathrm{IC}_{50}=7.9 \mu \mathrm{M}$ ). However, in the case of A549/taxol cells this $\mathrm{IC}_{50}$ was reduced to $1.62 \mu \mathrm{M}$ when these cells were exposed to 50:50 ratios of cliotide CT2 and paclitaxel [68], which is another well-established anticancer drug [69]. These observations indicated a synergistic action between paclitaxel and cliotide CT2 and showed that the peptide was able to chemosensitize cancer cells to conventional anticancer drugs [68]. A similar chemosensitizing ability has been demonstrated for a number of other cyclotides in combination with doxorubicin and it was suggested that this synergistic interaction resulted from the ability of cyclotides to disrupt cellular membranes, thereby allowed increased uptake of doxorubicin into drug resistant cells [70].

A number of ADHPs have been identified in plants of the Violaceae family (Table 1), including cycloviolacin O24 (net charge -2) from Viola odorata along with varv $\mathrm{H}$ and vitri B (net charges -1 in both cases) from Viola philippica, which are both common horticultural plants $[71,72]$. These peptides possessed $\mathrm{IC}_{50}$ values, which ranged between $6.2 \mu \mathrm{M}$ and 16 $\mu \mathrm{M}$ and were found to possess activity against cell lines of human gliomablastoma cells (U251) and CEM-SS cells [67, 72]. Strong activity against these latter cancer cells was also reported for a trio of AHDPs (IC 50 values $1.7 \mu \mathrm{M}$ to $4.5 \mu \mathrm{M}$ ) named cycloviolacins Y1 (net charge -2), Y4 (net charge -1) and Y5 (net charge -1), which were identified in Viola yedoensis (Wild Chinese violet), an important herb in Chinese medicine [67]. In contrast, vaby D (net charge 1) was isolated from Viola abyssinica which grows in extreme habitats and altitudes in the Ethiopian Highlands. The peptide was found to have a broad spectrum of anticancer activity with $\mathrm{IC}_{50}$ values ranging between $3 \mu \mathrm{M}$ to $47 \mu \mathrm{M}$ when directed against a variety of cancers, including hepatocellular carcinoma cells (BEL-7402), and breast carcinoma (MDA-MB-231) 
[42, 73]. More recently, the mechanisms underpinning the activity of the peptide to U-937 GTB lymphoma cells was investigated, which suggested that, in addition to targeting the membranes of these cells, the peptide may be taken up to inflict damage on DNA and other internal targets [74].

It is generally accepted that the ability of cyclotides to interact with membranes is facilitated by the rigid molecular topology possessed by the vast majority of these peptides, which is characterized by a cystine knot motif embedded in a macrocyclic backbone (Figure 4) [4143]. This topology provides a molecular framework, which includes six backbone loops that define hydrophilic and hydrophobic surface regions (Figure 4) [41-43], thereby giving the tertiary structure of these molecules amphiphilic characteristics that allow partitioning into biological bilayers [75, 76]. However, based on structural differences in their molecular framework, cyclotides can be divided into a number of groups [41, 42], including two major subfamilies, generally known as the Möbius and bracelet peptides (Figure 4) [15, 77], and a much smaller group termed chimeric cyclotides [65]. The Möbius and bracelet subfamilies have fundamentally different molecular architectures that are primarily distinguished by the presence of a conserved proline residue in cis conformation in loop 5 of the former subfamily, causing a $180^{\circ}$ twist in the loop, which is not seen in the latter subfamily [15, 77]. Most of the cyclotide aHPDs with anticancer activity have been shown to belong to either the Möbius or the bracelet subfamilies (Table 2) with typical examples including: kalata B2 [78] and cycloviolacin Y4 [79] respectively (Figure 2). However, the molecular architectures of chimeric cyclotides include structural characteristics of both the Möbius and bracelet subfamilies [65] and include: cycloviolacin Y1 [79] and palicourein [65] (Table 2).

The differing topologies of Möbius and bracelet cyclotides lead to differences in their modes of membrane interaction, which primarily relates the clustering pattern of apolar 
residues that form the hydrophobic surface patches possessed by these peptides. These residues and patches make the major hydrophobic contribution to the membrane partitioning of cyclotides and are mainly centred on loops 5 and 6 of Möbius peptides and loops 2 and 3 of bracelet peptides [80], as shown for kalata B2 and cycloviolacin Y4 in Figure 4. However, the electrostatic contribution to the membrane partitioning of both subfamilies appears to involve hydrophilic patches formed primarily by the presence of positively charged residues in loops 5 and 6 of these peptides (Figure 4) [80, 81]. Examples of this residue distribution can be seen in most cyclotide anticancer AHPDs, including: kalata B2, which has an arginine residue in loop 6 [78], and cycloviolacin Y5, which has a lysine residue in this loop [67]. Although anionic overall, these AHPDs are effectively functioning as CHDPs by utilising their cationic residues as major promoters of the electrostatic contribution to their membrane partitioning [27]. However, other cyclotide AHPDs with anticancer activity, such as cycloviolacin Y4 and cycloviolacin O24, lack cationic residues and the only anionic residue in loops 5 and 6 of these peptides is a single aspartic acid residue in loop 5 of cycloviolacin O24 [71, 79]. In these cases, it has been proposed that the strongly hydrophobic nature of loops 5 and 6 would most likely be the major driving force behind the membrane partitioning of these peptides [67]. Currently, the role of negatively charged residues in the membrane interactions of not only cyclotide AHDPs but also other members of this peptide family is generally unclear [27].

Major investigation into the interactions of cylotide ADHPs with naturally occurring cancer cell membranes do not appear to have been yet undertaken and most of the understanding in relation to these interactions derives from studies on models and mimics of these membranes [62, 75, 76, 81, 82]. However, these studies have shed some light on the role of negatively charged residues in cyclotides and have established that an essential requirement for the membrane interactions appears to be the possession of a conserved glutamate residue 
in loop 1 of their molecular framework [83]. This residues participates in a structurally important network of hydrogen bonds to the adjacent loop 3 and is depicted in the primary and tertiary structures of kalata B2 and cycloviolacin Y4 in Figure 2 [83]. The sole exception to this requirement appears to be kalata B12 (net charge-2), which is another of the ADHPs found in O. affinis [84] and has an aspartate residue substituted in the otherwise conserved glutamate position [83]. As is believed for ADHPs in general [22, 23, 27], their counterparts within the cylotides do not appear to require protein receptors to facilitate their membrane interactions [85] although the universality of this belief is in question [38, 86]. Most recently, kalata B2 and a number of other AHDPs within the cyclotides were found to show a strong preference for phosphatidyl ethanolamine (PE) in their membrane interactions, which led to the suggestion that PE may serve as a lipid receptor for these peptides [62, 81, 82]. The conserved glutamate of kalata B2, and other AHDPs, appeared to play a primary role in their PE-binding mechanisms through ionic interactions between the residue's carboxylate side-chain and the ammonium group of the lipid. These interactions were stabilised by non-specific hydrophobic associations between hydrophobic patches on the surface of kalata B2 and lipid acyl chains forming the apolar bilayer core region [62, 81, 82]. To investigate this suggestion, here, we undertook molecular dynamic simulations of kalata B2 interacting with a bilayer constructed from DMPE (Figure 5). These simulations predicted that the peptide possessed high affinity for these bilayers and bound strongly to the lipid head-group region of the membrane, which would support the suggested receptor role for the lipid [62, 81, 82]. These simulations further predicted that PE-binding by kalata B2 involved electrostatic and hydrogen-bond interactions between residues in loops 2, 3 and 6 of the peptide and phosphate and ammonium moieties within the head-group region of the bilayer (Figure 5), which is also in good general agreement with previous work [62, 81, 82]. However, our simulations also predicted that the conserved glutamate of PE-bound kalata B2 was distal from the membrane surface and was not involved 
in this binding mechanism (Figure 5), contrasting to previous experimental work [62, 81, 82]. One likely explanation for this apparent difference would seem to be that other components and / or properties of the model membranes used in these latter studies play a role in stabilizing the glutamate-mediated orientation of kalata B2 when binding to the PE head-group and clearly, these membrane components and properties are not replicated in the relatively simple lipid system used in our molecular dynamic simulations.

Although it is generally accepted that the anticancer activity of AHDPs from cyclotides involves membrane interaction, the mechanisms underpinning these actions are poorly understood [15, 41]. In response, there have been a number of studies on kalata B2 [62, 75, 76, 81, 82], which suggested that the peptide may utilise a variant of the toroidal pore mechanism $[62,82]$, one of the most commonly used mechanisms of membrane perturbation used by HDPs [87]. Experimental data, which strongly favoured this suggestion, led to a model for the membrane interactions of kalata B2 and other ADHPs, which is shown in Figure 6 [82]. According to this model, monomers or oligomers of kalata B2 approach the membrane surface (Figure 6A) and specifically bind PE head-groups whilst concomitantly interacting nonspecifically with the lipid’s acyl chains (Figure 6B). It has previously been shown that kalata B2 is able to form tetramers and octamers in aqueous solution [88] although more recent studies have suggested that these oligomers are unlikely to be the functional units involved in pore formation by the peptide [89]. This model then proposes that the progressive aggregation of kalata B2 molecules on the membrane surface, either as monomers or loosely packed oligomers, imposes a positive curvature strain by increasing the distance between membrane lipid head-groups, an effect usually described as membrane thinning. Once the localized concentration of kalata B2 molecules on the membrane surface reaches a threshold value, they insert into the bilayer whilst remaining in contact with the PE head-group. This action leads to 
cavitation of the membrane surface and ultimately, the formation of toroidal pores that are lined by lipid head-groups and hydrophilic surfaces of the participating cyclotide molecules (Figure 6C). This process continues until high concentrations of kalata B2 are reached when lipids are extracted from the membrane, which results in solubilisation and ultimately, disintegration of the bilayer (Figure 6D) [62, 75, 76, 81, 82]. It has been also suggested that ADHPs from cyclotides may use other mechanisms of membranolysis [22] and, as described above, more recent studies on the anticancer activity of vaby $\mathrm{D}$ have suggested that the peptide may be able to attack internal targets of cancer cells [74]. This ability would be consistent with use of the Shai, Huang and Matsazuki model of membrane perturbation [87], which appears to be used by some non-plant AHDPs [27, 90] and includes the toroidal pore mechanism but allows for the internalization of peptides via transient pore formation [87].

\section{Discussion}

In this review, over a dozen AHDPs with anticancer activity have been described from sources across the plant kingdom, ranging from garden plants such as violets of the Violaceae to tropical plants such as palm trees of the Arecaceae (Table 1). In general, these peptides are effective against a wide variety of human cancers cells, including some of the more deadly forms of the condition such as glioblastoma (Table 2). As to why these AHDPs possess the capacity for anticancer activity is unclear as, self-evidently, this capacity has no relevance to plant survival [85]. However, it has been suggested that this anticancer activity may result from the general ability of these peptides to interact with membranes [86], which appears to have evolved to kill microorganisms in line with the role of most HDPs as endogenous antimicrobials [39]. This review has shown that the anticancer actions used by plant AHPDs are based on membrane interaction, which at least in some cases, appears to involve the use of 
PE as a lipid receptor (Figure 4). This would appear to be one of the first instances of such use by these AHDPs although a similar use of the lipid has been reported for several non-plant AHDPs [91-93], including some with anticancer activity such as maximin H5 from amphibians [36]. This review has also shown that the membrane partitioning of plant AHDPs with anticancer activity leads to membranolysis and / or internalization to attack intracellular targets such as DNA and several models have been proposed to describe these events (Figures 2 and 5). These models include: the toroidal pore and Shai-Matsuzaki-Huang mechanisms but, in general, the mechanisms underpinning the membrane interactions and anticancer activity of AHPDs from plants are poorly understood. The membrane interactive structures used by these peptides are diverse and include extended conformations and $\alpha$-helical architecture although the majority are based on cysteine stabilized scaffolds, which are by far the most common structures found in plant HDPs [19]. A few of the AHDPs described here have net charges of -2 although most have a net charge of -1 , which would seem to suggest that low levels of anionicity are required for their membrane interactions and anticancer activity. In relation to the roles of specific anionic residues in this activity, it has been established that conserved glutamate residues in cyclotides play important structural roles in the membrane interactions of these peptides as well as helping to facilitate binding to PE receptors. A structural role has also been suggested for aspartate residues in the case of $\alpha$-helical HDPs such as $C r$-ACP1 where they tend to occupy positions that are $i \pm 3$ or $i \pm 4$ relative to basic residues. It has been suggested that this structural positioning may promote helix formation via salt bridging and thereby serve as a strategy to stabilise $\alpha$-helical structure [38].

However, in the vast majority of cases, detailed descriptions of the role played by anionic residues in the anticancer action of AHDPs from plants is lacking. 
In their native form, there are a number of issues attached to the use of the AHDPs described here as therapeutically viable anticancer agents. In the case of $\mathrm{Cr}$-ACP1 and $\mathrm{Cn}$ AMP2, the millimolar levels of these peptides required to elicit an anticancer response is obviously prohibitive to such use. However, it has been observed that AHDPs such as CnAMP2 that are devoid of cationic residues possess an advantage over CHDPs with anticancer action whose possession of lysine and arginine residues makes them highly susceptible to degradation by human proteases $[94,95]$. This suggests that the intrinsic properties of $C r$-ACP1 and similar AHDPs, such as cycloviolacin Y4 and cycloviolacin O24, which also lack cationic residues, may endow them with anticancer mechanisms that are not available to their cationic counterparts making them attractive propositions as candidates for therapeutic development. For example, these compounds may be effective against cancer cells with multiple drug resistance that has rendered CHDPs ineffective when directed against these cells.

In their native form most AHDPs from cyclotides have anticancer activity in the low micromolar range, which is approaching therapeutically desirable levels but many of these peptides are non-selective for cancer cells and possess potent haemolytic action, such as kalata B2 and cliotide T3 [22]. However, other AHDPs from cyclotides with anticancer action such as kalata B13 and vaby D show no evidence of haemolytic action and may therefore be suitable for development in the treatment of cancerous conditions [22]. Indeed, vaby D would seem to be a good candidate for such development given that the peptide shows by far the broadest range of anticancer activity of the cyclotide AHDPs so far tested in this capacity (Table 1). Moreover, many AHDPs from this plant family are known but have yet to be tested for anticancer activity [22] whilst others are increasingly being identified such as the recently reported Viphi H (net charge -1) from Viola philippica of the Violaceae [96]. Indeed, it has been predicted the total number of cyclotides in the Rubiaceae alone exceeds 50,000, which 
would seem to indicate that there are large numbers of AHDPs within the cyclotides with the potential for anticancer activity yet to be identified [47].

This review has shown that a number of AHDPs have the potential to act as templates in the development of novel compounds with the ability to kill a range of cancers. In this capacity, as shown by this review, AHDPs from cyclotides are by far the most researched and it is becoming increasingly clear that their anticancer potential may be achieved through progress in deriving synthetic versions of these peptides [22]. The high plasticity and tolerance to substitution of the cyclotide scaffold is now well established and several studies have clearly shown that bioactive peptide sequences can be efficiently grafted into these scaffold for a variety of therapeutic purposes, including the production of compounds with anticancer capacity [48, 97]. For example, PE shows the potential to serve as a biomarker for many malignancies [98] and it has been proposed that derivatives of PE-binding cyclotides may be suitable for development as agents in tumour imaging and anticancer therapeutics $[75,76,81$, 99, 100]. As another example, it may be possible to optimise the membrane-permeabilizing ability of cyclotides through scaffold modification to efficiently synergise the action of established anticancer drugs, as described above for cliotide CT2 and paclitaxel [68]. Proof-ofconcept for such work was recently demonstrated when a grafted cyclotide, showed activity against growth factors involved in angiogenesis [101]; it is well-established that tumor growth is usually associated with unregulated angiogenesis [102]. As further proof-of-concept, more recently, work, which was patented [103], demonstrated that engineered cyclotides were cytotoxic to cancer cells through activation of the p53 tumor suppressor pathway, which is commonly inactivated by these cells to promote survival [104].

In summary, here we have presented the first major review of research into AHDPs from plants with anticancer activity. It is clear from this review that although this research is 
its infancy, these peptides have the potential to serve as therapeutically useful anticancer agents. However, to achieve this potential a much greater understanding of factors such as their pharmacokinetics and modes of anticancer action needs to be acquired. Nonetheless, given this understanding, plant AHDPs may prove to be a major untapped source of answers to the rapidly increasing global problem of cancer [105].

\section{References}

1. Phoenix, D.A., S.R. Dennison, and F. Harris, Antimicrobial Peptides: Their History, Evolution, and Functional Promiscuity, in Antimicrobial Peptides. 2013, Wiley-VCH Verlag GmbH \& Co. KGaA. p. 1-37.

2. Jones, J.D.G. and J.L. Dangl, The plant immune system. Nature, 2006. 444(7117): p. 323-329.

3. Spoel, S.H. and X. Dong, How do plants achieve immunity? Defence without specialized immune cells. Nature Reviews Immunology, 2012. 12(2): p. 89-100.

4. $\quad$ Sels, J., et al., Plant pathogenesis-related (PR) proteins: A focus on PR peptides. Plant Physiology and Biochemistry, 2008. 46(11): p. 941-950.

5. De Lucca, A.J., T.E. Cleveland, and D.E. Wedge, Plant-derived antifungal proteins and peptides. Can J Microbiol, 2005. 51(12): p. 1001-1014.

6. Borad, V. and S. Sriram, Pathogenesis-Related Proteins for the Plant Protection. Asian Journal of Experimental Sciences, 2008. 22(3): p. 189-196.

7. Edreva, A., Pathogenesis-related proteins: Research progress in the last 15 years. General Applied Plant Physiology. , 2005. 31(1-2): p. 105-124.

8. van Loon, L.C., M. Rep, and C.M.J. Pieterse, Significance of inducible defense-related proteins in infected plants, in Annual Review of Phytopathology. 2006. p. 135-162.

9. Van Loon, L.C. and E.A. Van Strien, The families of pathogenesis-related proteins, their activities, and comparative analysis of PR-1 type proteins. Physiological and Molecular Plant Pathology, 1999. 55(2): p. 85-97. 
10. Ribeiro, S.M., S.C. Dias, and O.L. Franco, Plant Antimicrobial Peptides: From Basic Structures to Applied Research, in Peptide Drug Discovery and Development. 2011, Wiley-VCH Verlag GmbH \& Co. KGaA. p. 139-155.

11. Tavares, L.S., et al., Biotechnological potential of antimicrobial peptides from flowers. Peptides, 2008. 29(10): p. 1842-1851.

12. Barbosa Pelegrini, P., et al., Antibacterial peptides from plants: what they are and how they probably work. Biochemistry research international, 2011. 2011: p. 250349.

13. Hammami, R., et al., PhytAMP: a database dedicated to antimicrobial plant peptides. Nucleic Acids Res, 2009. 37(Database issue): p. D963-8.

14. Carvalho, A.d.O. and V.M. Gomes, Plant defensins and defensin-like peptides biological activities and biotechnological applications. Current pharmaceutical design, 2011. 17(38): p. 4270-93.

15. Pinto, M.F.S., I.C.M. Fensterseifer, and O.L. Franco, Plant Cyclotides: An Unusual Protein Family with Multiple Functions, in Plant Defence: Biological Control, J.M. Merillon and K.G. Ramawat, Editors. 2012. p. 333-344.

16. Egorov, T.A. and T.I. Odintsova, Defense Peptides of Plant Immunity. Russian Journal of Bioorganic Chemistry, 2012. 38(1): p. 1-9.

17. Octavio Luiz, F., Peptide promiscuity: An evolutionary concept for plant defense. FEBS Letters, 2011. 585(7): p. 995-1000.

18. Benko-Iseppon, A.M., et al., Overview on Plant Antimicrobial Peptides. Current Protein \& Peptide Science, 2010. 11(3): p. 181-188.

19. Padovan, L., M. Scocchi, and A. Tossi, Structural Aspects of Plant Antimicrobial Peptides. Current Protein \& Peptide Science, 2010. 11(3): p. 210-219.

20. López-García, B., B.S. Segundo, and M. Coca, Antimicrobial Peptides as a Promising Alternative for Plant Disease Protection, in Small Wonders: Peptides for Disease Control. 2012, American Chemical Society. p. 263-294.

21. Svetlana, O., H. Jong Hyun, and C. Marc Alan, Thionins - Nature?s Weapons of Mass Protection, in Small Wonders: Peptides for Disease Control. 2012, American Chemical Society. p. 415-443.

22. Prabhu, S., et al., Anionic Antimicrobial and Anticancer Peptides from Plants. Critical Reviews in Plant Sciences, 2013. 32(5): p. 303-320.

23. Harris, F., S.R. Dennison, and D.A. Phoenix, Anionic Antimicrobial Peptides from Eukaryotic Organisms. Current Protein \& Peptide Science, 2009. 10(6): p. 585-606.

24. Wang, G., X. Li, and Z. Wang, APD2: the updated antimicrobial peptide database and its application in peptide design. Nucleic Acids Research, 2009. 37: p. D933-D937.

25. Wang, G., X. Li, and M. Zasloff, A Database View of Naturally Occurring Antimicrobial Peptides: Nomenclature, Classification and Amino Acid Sequence Analysis. Antimicrobial Peptides: Discovery, Design and Novel Therapeutic Strategies, ed. G. Wang. 2010. 1-21.

26. Sarika, M.A. Iquebal, and A. Rai, Biotic stress resistance in agriculture through antimicrobial peptides. Peptides, 2012. 36(2): p. 322-330.

27. Harris, F., S.R. Dennison, and D.A. Phoenix, Anionic Antimicrobial Peptides from Eukaryotic Organisms and their Mechanisms of Action. Current Chemical Biology, 2011. 5(2): p. 142-153.

28. Phoenix, D.A., S.R. Dennison, and F. Harris, Anionic Antimicrobial Peptides, in Antimicrobial Peptides. 2013, Wiley-VCH Verlag GmbH \& Co. KGaA. p. 83-113. DOI: $\quad 10.1002 / 9783527652853 . c h 3$ (available at: http://onlinelibrary.wiley.com/doi/10.1002/9783527652853.ch3/summary) 
29. Mourya, M.K., et al., Leaves of cycas revoluta: potent antimicrobial andantioxidant agent. World Journal of Science and Technology, 2011. 1: (10): p. 11-20.

30. Mandal, S.M., et al., Identification and characterization of a bactericidal and proapoptotic peptide from cycas revoluta seeds with DNA binding properties. Journal of Cellular Biochemistry, 2012. 113(1): p. 184-193.

31. Phoenix, D.A. and F. Harris, The hydrophobic moment and its use in the classification of amphiphilic structures (Review). Molecular Membrane Biology, 2002. 19(1): p. 110.

32. Phoenix, D.A., et al., The prediction of amphiphilic alpha-helices. Current Protein \& Peptide Science, 2002. 3(2): p. 201-221.

33. Al-Benna, S., et al., Oncolytic Activities of Host Defense Peptides. International Journal of Molecular Sciences, 2011. 12(11): p. 8027-8051.

34. Prades, A., et al., Coconut water uses, composition and properties: a review. Fruits, 2012. 67(2): p. 87-107.

35. Prabhu, S., Effects of novel compounds in an in vitro chemosensitivity system for glioma treatment. 2012, University of Central Lancashire: UK.

36. Prabhu, S., et al. Characterisation of an anionic anticancer peptide isolated from green coconut water. in UK-Netherlands Joint Symposium on Antimicrobial peptides: Isolation, characterization, modification and applications. . 2011. University of Durham, UK.

37. Prabhu, S., et al., Cn-AMP2 from green coconut water is an anionic anticancer peptide. Journal of Peptide Science, 2014. In press.

38. Harris, F., et al., On the selectivity and efficacy of defense peptides with respect to cancer cells. Medicinal Research Reviews, 2013. 33(1): p. 190-234.

39. Phoenix, D.A., S.R. Dennison, and F. Harris, Cationic Antimicrobial Peptides, in Antimicrobial Peptides. 2013, Wiley-VCH Verlag GmbH \& Co. KGaA. p. 39-81. DOI: 10.1002/9783527652853.ch2 (available at: http://onlinelibrary.wiley.com/doi/10.1002/9783527652853.ch2/summary)

40. Chan, D.I., E.J. Prenner, and H.J. Vogel, Tryptophan- and arginine-rich antimicrobial peptides: Structures and mechanisms of action. Biochimica Et Biophysica ActaBiomembranes, 2006. 1758(9): p. 1184-1202.

41. Craik, D.J., Host-defense activities of cyclotides. Toxins, 2012. 4(2): p. 139-56.

42. Gerlach, S.L. and D. Mondal, The bountiful biological activities of cyclotides. Chron Young Sci, 2012. 3: p. 169-77.

43. Craik, D.J., Joseph Rudinger memorial lecture: Discovery and applications of cyclotides. Journal of Peptide Science, 2013. 19(7): p. 393-407.

44. Wang, C.K.L., et al., CyBase: a database of cyclic protein sequences and structures, with applications in protein discovery and engineering. Nucleic Acids Research, 2008. 36: p. D206-D210.

45. Mulvenna, J.P., C. Wang, and D.J. Craik, CyBase: a database of cyclic protein sequence and structure. Nucleic Acids Research, 2006. 34: p. D192-D194.

46. Koehbach, J., et al., Cyclotide discovery in Gentianales revisited-identification and characterization of cyclic cystine-knot peptides and their phylogenetic distribution in Rubiaceae plants. Biopolymers, 2013. 100(5): p. 438-52.

47. Gruber, C.W., et al., Distribution and Evolution of Circular Miniproteins in Flowering Plants. Plant Cell, 2008. 20(9): p. 2471-2483.

48. Daly, N.L., K.J. Rosengren, and D.J. Craik, Discovery, structure and biological activities of cyclotides. Advanced Drug Delivery Reviews, 2009. 61(11): p. 918-930. 
49. Camarero, J.A., Legume cyclotides shed light on the genetic origin of knotted circular proteins. Proceedings of the National Academy of Sciences of the United States of America, 2011. 108(25): p. 10025-10026.

50. Giang, K.T.N., et al., Discovery and Characterization of Novel Cyclotides Originated from Chimeric Precursors Consisting of Albumin-1 Chain a and Cyclotide Domains in the Fabaceae Family. Journal of Biological Chemistry, 2011. 286(27): p. 24275-24287.

51. Poth, A.G., et al., Discovery of an unusual biosynthetic origin for circular proteins in legumes. Proceedings of the National Academy of Sciences of the United States of America, 2011. 108(25): p. 10127-10132.

52. Poth, A.G., et al., Discovery of Cyclotides in the Fabaceae Plant Family Provides New Insights into the Cyclization, Evolution, and Distribution of Circular Proteins. Acs Chemical Biology, 2010. 6(4): p. 345-355.

53. Tang, J. and N.H. Tan, Progress of Cyclotides in Plants. Progress in Chemistry, 2010. 22(4): p. 677-683.

54. Poth, A.G., et al., Cyclotides Associate with Leaf Vasculature and Are the Products of a Novel Precursor in Petunia (Solanaceae). Journal of Biological Chemistry, 2012. 287(32): p. 27033-27046.

55. Nguyen, G.K.T., et al., Discovery of Linear Cyclotides in Monocot Plant Panicum laxum of Poaceae Family Provides New Insights into Evolution and Distribution of Cyclotides in Plants. Journal of Biological Chemistry, 2013. 288(5): p. 3370-3380.

56. Gran, L., An oxytocic principle found in Oldenlandia affinis DC. Meddelelser fra Norsk Farmaceutisk Selskap, 1970. 32(12): p. 173-180.

57. Gran, L., On the effect of a polypeptide isolated from "Kalata-Kalata" (Oldenlandia affinis DC) on the oestrogen dominated uterus. Acta Pharmacol Toxicol (Copenh), 1973. 33(5): p. 400-408.

58. Gruber, C.W. and M. O'Brien, Uterotonic Plants and their Bioactive Constituents. Planta Medica, 2011. 77(3): p. 207-220.

59. Gran, L., OXYTOCIC PRINCIPLES OF OLDENLANDIA-AFFINIS. Lloydia-the Journal of Natural Products, 1973. 36(2): p. 174-178.

60. Gran, L., F. Sandberg, and K. Sletten, Oldenlandia affinis (R\&S) DC - A plant containing uteroactive peptides used in African traditional medicine. Journal of Ethnopharmacology, 2000. 70(3): p. 197-203.

61. Gran, L., K. Sletten, and L. Skjeldal, Cyclic peptides from Oldenlandia affinis DC. Molecular and biological properties. Chem Biodivers, 2008. 5(10): p. 2014-2022.

62. Burman, R., et al., Cyclotide-membrane interactions: Defining factors of membrane binding, depletion and disruption. Biochimica Et Biophysica Acta-Biomembranes, 2011. 1808(11): p. 2665-2673.

63. Burman, R., et al., Cytotoxic potency of small macrocyclic knot proteins: Structureactivity and mechanistic studies of native and chemically modified cyclotides. Organic \& Biomolecular Chemistry, 2011.9(11): p. 4306-4314.

64. Tacar, O., P. Sriamornsak, and C.R. Dass, Doxorubicin: an update on anticancer molecular action, toxicity and novel drug delivery systems. Journal of Pharmacy and Pharmacology, 2012: p. no-no.

65. Bokesch, H.R., et al., A novel anti-HIV macrocyclic peptide from Palicourea condensata. Journal of Natural Products, 2001. 64(2): p. 249-250.

66. Nguyen, G.K.T., et al., Novel Cyclotides and Uncyclotides with Highly Shortened Precursors from Chassalia chartacea and Effects of Methionine Oxidation on Bioactivities. Journal of Biological Chemistry, 2012. 287(21): p. 17598-17607. 
67. Ireland, D.C., et al., Cyclotides as natural anti-HIV agents. Biopolymers, 2008. 90(1): p. 51-60.

68. Sen, Z., et al., Chemosensitizing activities of cyclotides from Clitoria ternatea in paclitaxel-resistant lung cancer cells. Oncology Letters, 2013. 5(2): p. 641-644.

69. Zhang, Z., L. Mei, and S.-S. Feng, Paclitaxel drug delivery systems. Expert Opinion on Drug Delivery, 2013. 10(3): p. 325-340.

70. Gerlach, S.L., et al., Anticancer and chemosensitizing abilities of cycloviolacin $\mathrm{O} 2$ from Viola odorata and psyle cyclotides from Psychotria leptothyrsa. Peptide Science, 2010. 94(5): p. 617-625.

71. Ireland, D.C., M.L. Colgrave, and D.J. Craik, A novel suite of cyclotides from Viola odorata: sequence variation and the implications for structure, function and stability. Biochem J, 2006. 400(1): p. 1-12.

72. Tang, J., et al., Isolation and characterization of cytotoxic cyclotides from Viola tricolor. Peptides, 2010. 31(8): p. 1434-1440.

73. Yeshak, M.Y., et al., Cyclotides from an Extreme Habitat: Characterization of Cyclic Peptides from Viola abyssinica of the Ethiopian Highlands. Journal of Natural Products, 2011. 74(4): p. 727-731.

74. Yeshak, M.Y., et al., Genotoxicity and cellular uptake of cyclotides: Evidence for multiple modes of action. Mutation Research/Genetic Toxicology and Environmental Mutagenesis, 2012. 747(2): p. 176-181.

75. Henriques, S.T. and D.J. Craik, Importance of the Cell Membrane on the Mechanism of Action of Cyclotides. Acs Chemical Biology, 2012. 7(4): p. 626-636.

76. Henriques, S.T., et al., The Importance of the Cell Membrane on the Mechanism of Action of Cyclotides. Journal of Peptide Science, 2012. 18: p. S148-S149.

77. Craik, D.J., et al., Plant cyclotides: A unique family of cyclic and knotted proteins that defines the cyclic cystine knot structural motif. Journal of Molecular Biology, 1999. 294(5): p. 1327-1336.

78. Jennings, C.V., et al., Isolation, solution structure, and insecticidal activity of kalata B2, a circular protein with a twist: do Mobius strips exist in nature? Biochemistry, 2005. 44(3): p. 851-860.

79. Wang, C.K., et al., Anti-HIV cyclotides from the Chinese medicinal herb Viola yedoensis. J Nat Prod, 2008. 71(1): p. 47-52.

80. Wang, C.K., et al., Despite a Conserved Cystine Knot Motif, Different Cyclotides Have Different Membrane Binding Modes. Biophysical Journal, 2009. 97(5): p. 1471-1481.

81. Henriques, S.T., Phosphatidylethanolamine-binding is a conserved feature of cyclotide-membrane interactions. JBC, 2012.

82. Wang, C.K., H.P. Wacklin, and D.J. Craik, Cyclotides Insert into Lipid Bilayers to Form Membrane Pores and Destabilize the Membrane through Hydrophobic and Phosphoethanolamine-specific Interactions. Journal of Biological Chemistry, 2012. 287(52): p. 43884-43898.

83. Wang, C.K.L., et al., The Role of Conserved Glu Residue on Cyclotide Stability and Activity: A Structural and Functional Study of Kalata B12, a Naturally Occurring Glu to Asp Mutant. Biochemistry, 2011. 50(19): p. 4077-4086.

84. Plan, M.R., et al., The cyclotide fingerprint in oldenlandia affinis: elucidation of chemically modified, linear and novel macrocyclic peptides. Chembiochem, 2007. 8(9): p. 1001-1011.

85. Sando, L., et al., A Synthetic Mirror Image of Kalata B1 Reveals that Cyclotide Activity Is Independent of a Protein Receptor. Chembiochem, 2011. 12(16): p. 2456-2462. 
86. Phoenix, D.A., S.R. Dennison, and F. Harris, Selectivity and Toxicity of Oncolytic Antimicrobial Peptides, in Antimicrobial Peptides. 2013, Wiley-VCH Verlag GmbH \& Co. KGaA. p. 181-221.

87. Phoenix, D.A., S.R. Dennison, and F. Harris, Models for the Membrane Interactions of Antimicrobial Peptides, in Antimicrobial Peptides. 2013, Wiley-VCH Verlag GmbH \& Co. KGaA. p. 145-180.

88. Nourse, A., et al., A comparison of the self-association behavior of the plant cyclotides kalata B1 and kalata B2 via analytical ultracentrifugation. Journal of Biological Chemistry, 2004. 279(1): p. 562-570.

89. Rosengren, K.J., et al., The self-association of the cyclotide kalata B2 in solution is guided by hydrophobic interactions. Biopolymers, 2013. 100(5): p. 453-60.

90. Hall, S.H., et al., Characterization and functions of beta defensins in the epididymis. Asian Journal of Andrology, 2007. 9(4): p. 453-462.

91. Soscia, S.J., et al., The Alzheimer's Disease-Associated Amyloid beta-Protein Is an Antimicrobial Peptide. Plos One, 2010. 5(3).

92. Cazzaniga, E., et al., Abeta Peptide Toxicity is Reduced After Treatments Decreasing Phosphatidylethanolamine Content in Differentiated Neuroblastoma Cells. Neurochemical Research, 2011. 36(5): p. 863-869.

93. Dennison, S.R., et al., A novel form of bacterial resistance to the action of eukaryotic host defense peptides, the use of a lipid receptor. Biochemistry, 2013. 52(35): p. 60219.

94. Cho, J.H. and S.C. Kim, Non-membrane Targets of Antimicrobial Peptides: Novel Therapeutic Opportunities? Antimicrobial Peptides: Discovery, Design and Novel Therapeutic Strategies, ed. G. Wang. 2010. 128-140.

95. Riedl, S., D. Zweytick, and K. Lohner, Membrane-active host defense peptides Challenges and perspectives for the development of novel anticancer drugs. Chemistry and Physics of Lipids, 2011. 164(8): p. 766-781.

96. He, W., et al., Isolation and characterization of cytotoxic cyclotides from Viola philippica. Peptides, 2011. 32(8): p. 1719-1723.

97. Craik, D.J., et al., Cyclotides as a basis for drug design. Expert Opinion on Drug Discovery, 2012. 7(3): p. 179-194.

98. Stafford, J.H. and P.E. Thorpe, Increased Exposure of Phosphatidylethanolamine on the Surface of Tumor Vascular Endothelium. Neoplasia, 2011. 13(4): p. 299-U125.

99. Henriques, S., Troeira. , et al., Anticancer and Toxic Properties of Cyclotides are Dependent on Phosphatidylethanolamine Phospholipid Targeting. Chembiochem, 2014. 15(13): p. 1956-1965.

100. Kimura, R.H. and S.S. Gambhir, Target-Specific Molecular Imaging with Cystine Knot Peptides. Amino Acids, 2013. 45(3): p. 608-608.

101. Gunasekera, S., et al., Engineering Stabilized Vascular Endothelial Growth Factor-A Antagonists: Synthesis, Structural Characterization, and Bioactivity of Grafted Analogues of Cyclotides. Journal of Medicinal Chemistry, 2008. 51(24): p. 7697-7704.

102. Liang, X., et al., VEGF Signal System: The Application of Antiangiogenesis. Current Medicinal Chemistry, 2014. 21(7): p. 894-910.

103. Camarero, J.A., et al., Novel cyclotides with anticancer activity. 2013, Google Patents.

104. Ji, Y., et al., In Vivo Activation of the p53 Tumor Suppressor Pathway by an Engineered Cyclotide. Journal of the American Chemical Society, 2013. 135(31): p. 11623-11633.

105. Bray, F., et al., Global cancer transitions according to the Human Development Index (2008-2030): a population-based study. Lancet Oncology, 2012. 13(8): p. 790-801. 
Published Harris F, et al 2016 Protein Pept Lett. 2016 May 11. [Epub ahead of print] PMID: 27165406

106. Mandal, S.M., et al., Identification and structural insights of three novel antimicrobial peptides isolated from green coconut water. Peptides, 2009. 30(4): p. 633-637. 
Published Harris F, et al 2016 Protein Pept Lett. 2016 May 11. [Epub ahead of print] PMID: 27165406

Table 1. Plants hosting AHDPs with anticancer activity.

\begin{tabular}{|c|c|c|c|c|}
\hline Family & Source plant & Peptide & Sequence & Refs \\
\hline \multicolumn{5}{|c|}{ Cycadaceae } \\
\hline & Cyas revolute & Cr-ACP1 & AWKLFDDGV & {$[30]$} \\
\hline \multicolumn{5}{|l|}{ Arecaceae } \\
\hline & Cocos nucifera & Cn-AMP2 & TESYFVFSVGM & [106] \\
\hline \multicolumn{5}{|l|}{ Rubiaceae } \\
\hline & Oldenlandia affinis & Kalata B2 & $\begin{array}{l}\text { GLPVCGETCFGGTCNT } \\
\text { PGCSCTWPICTRD }\end{array}$ & {$[78]$} \\
\hline & & Kalata B13 & $\begin{array}{l}\text { GLPVCGETCFGGTCNT } \\
\text { PGCACDPWPVCTRD }\end{array}$ & {$[84]$} \\
\hline & Chassalia chartacea & chaC1, & $\begin{array}{l}\text { GDACGETCFTGICFTA } \\
\text { GCSCNPWPTCTRN }\end{array}$ & {$[66]$} \\
\hline & $\begin{array}{l}\text { Palicourea } \\
\text { condensata }\end{array}$ & Palicourein & $\begin{array}{l}\text { CGETCRVIPVCTYSAAL } \\
\text { GCTCDDRSDGLCKRNG } \\
\text { DPTF }\end{array}$ & {$[65]$} \\
\hline \multicolumn{5}{|l|}{ Fabaceae } \\
\hline & Clitoria ternatea & Cliotide T2 & $\begin{array}{l}\text { GEFLKCGESCVQGECY } \\
\text { TPGCSCDWPICKKN }\end{array}$ & {$[50]$} \\
\hline & & Cliotide T3 & $\begin{array}{l}\text { GLPTCGETCTLGTCYV } \\
\text { PDCSCSWPICMKN }\end{array}$ & {$[50]$} \\
\hline \multicolumn{5}{|l|}{ Violaceae } \\
\hline & Viola abyssinica & Vaby D & $\begin{array}{l}\text { GLPVCGETCFGGTCNT } \\
\text { PGCTCDPWPVCTRN }\end{array}$ & {$[73]$} \\
\hline
\end{tabular}


Published Harris F, et al 2016 Protein Pept Lett. 2016 May 11. [Epub ahead of print] PMID: 27165406

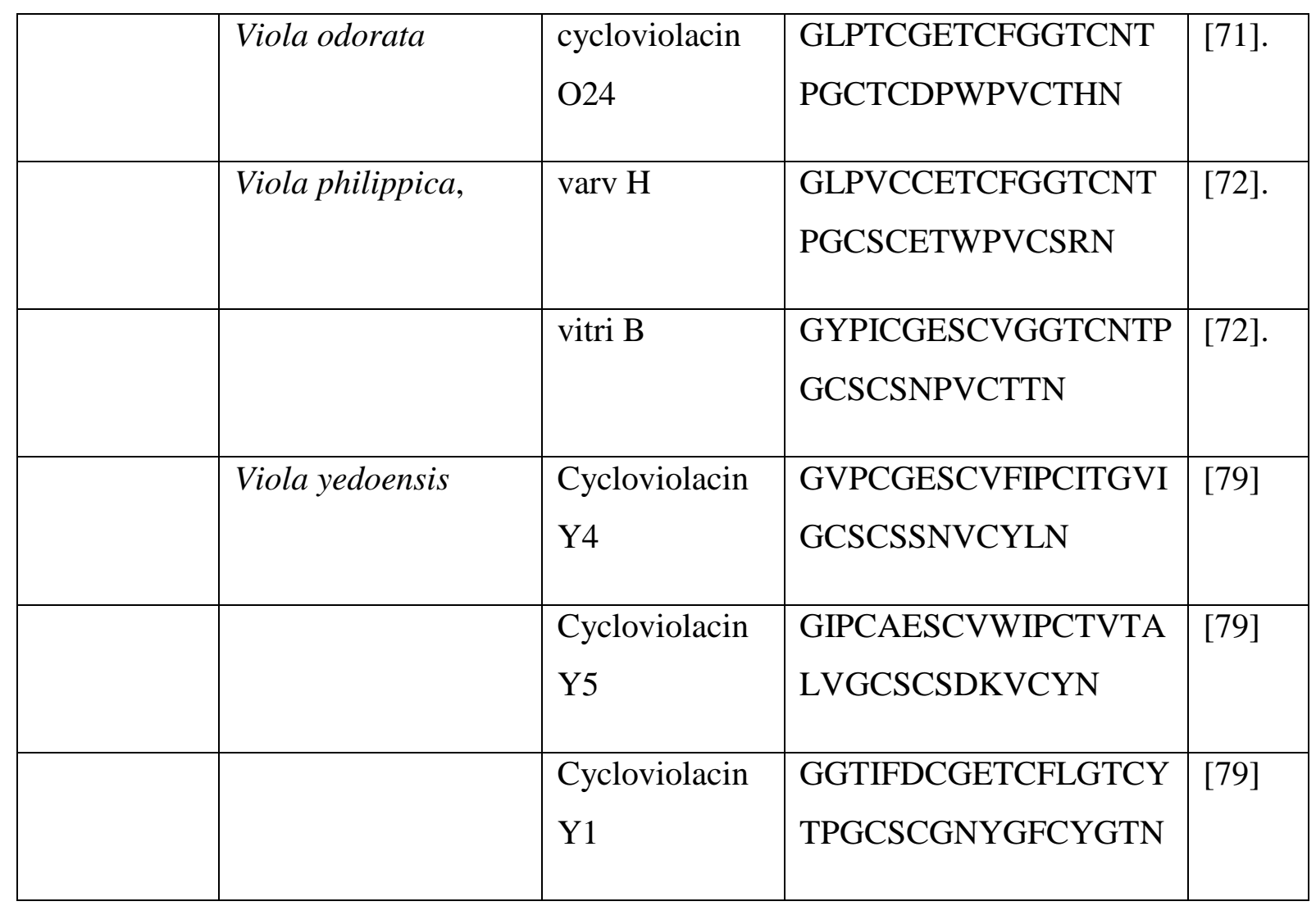


Table 2. Major AHDPs with anticancer activity

\begin{tabular}{|c|c|c|c|}
\hline Cyclotides & Charge & Anticancer activity & Refs \\
\hline Cn-AMP2 & -1 & Glioma (1321N1 and U87MG) & [106] \\
\hline Cr-ACP1 & -1 & Colon carcinoma (HCT15) and epidermoid cancer (Hp2) & [30] \\
\hline Kalata B2 $^{\mathbf{a}}$ & -1 & Lymphoma (U-937 GTB) colorectal cancer (Ht116) and colonadeno carcinoma (HT29) & {$[62,63]$} \\
\hline Kalata B13 ${ }^{\mathbf{a}}$ & -2 & Lymphoma (U-937 GTB) & [63] \\
\hline $\begin{array}{l}\text { cycloviolacin } \\
\text { O24a }\end{array}$ & -2 & Acute lymphoblastic leukaemia (CEM-SS) & [67] \\
\hline Vaby $\mathrm{D}^{\mathrm{a}}$ & -1 & $\begin{array}{l}\text { Lung cancer (A549), gastric carcinoma (BGC-823), hepatocellular carcinoma (BEL-7402), prostate cancer } \\
\text { (DU145), breast carcinoma (MDA-MB-231), gliomablastoma (U251) and lymphoma (U-937 GTB) }\end{array}$ & {$[42,73]$} \\
\hline Chac1 $^{\mathrm{a}}$ & -1 & Cervical cancer (HeLa) & [66] \\
\hline Cliotide T2 ${ }^{\mathbf{a}}$ & -1 & Cervical cancer (HeLa) and lung cancer (A549) & {$[50,68]$} \\
\hline Cliotide $\mathrm{T}^{\mathbf{a}}$ & -1 & Cervical cancer (HeLa) & [50] \\
\hline varv $\mathrm{H}^{\mathbf{b}}$ & -1 & Gliomablastoma (U251) & {$[72]$.} \\
\hline vitri $\mathrm{B}^{\mathbf{b}}$ & -1 & Gliomablastoma (U251) & {$[72]$.} \\
\hline $\begin{array}{l}\text { Cycloviolacin } \\
\text { Y4 }^{\mathbf{b}}\end{array}$ & -1 & Acute lymphoblastic leukaemia (CEM-SS) & [67] \\
\hline $\begin{array}{l}\text { Cycloviolacin } \\
\text { Y5 }^{\mathbf{b}}\end{array}$ & -1 & Acute lymphoblastic leukaemia (CEM-SS) & {$[67]$} \\
\hline $\begin{array}{l}\text { Cycloviolacin } \\
\text { Y1c }\end{array}$ & -2 & Acute lymphoblastic leukaemia (CEM-SS) & [67] \\
\hline Palicourein $^{c}$ & -1 & Acute lymphoblastic leukaemia (CEM-SS) & [67] \\
\hline
\end{tabular}

Table 2 shows AHDPs from plants and their target cancer cells. Membership of the Möbius subfamily of cyclotides is denoted by a and membership of the bracelet subfamily is indicated by ${ }^{\mathbf{b}}$. Chimeric cyclotides, which include structural characteristics of both the and bracelet subfamilies, are denoted by ${ }^{\mathbf{c}}$. Details of the characterisation of these AHDPs is supplied in the associated references. 
Published Harris F, et al 2016 Protein Pept Lett. 2016 May 11. [Epub ahead of print] PMID: 27165406 


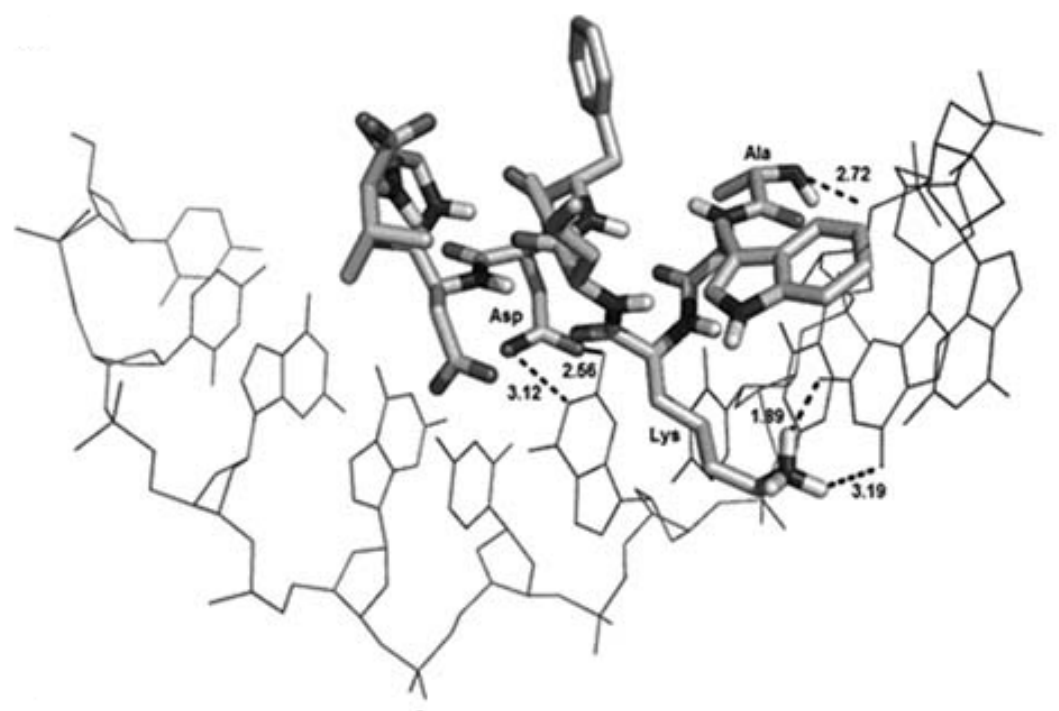

Figure 1 was adapted from [30] and shows a binary complex formed between Cr-ACP1 and single stranded DNA 5'-CCGGC-3', modelled to represent the strong affinity for DNA by the peptide in experimental work. Lateral chains involved in the formation of this complex are labelled with dotted lines indicating hydrogen bonds and their respective distances given in angstroms. Based on this model, DNA binding by the peptide was predicted to involve the ability of its charged and polar residues to form a stable hydrogen bond network with DNA nucleotides. 
Figure 2. The effects of Cn-AMP2 on the morphology of cell lines

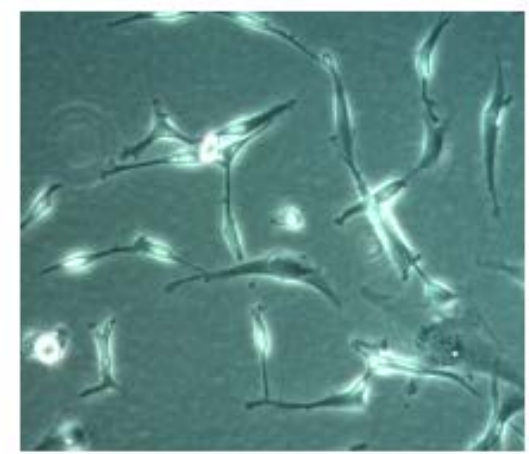

U87MG

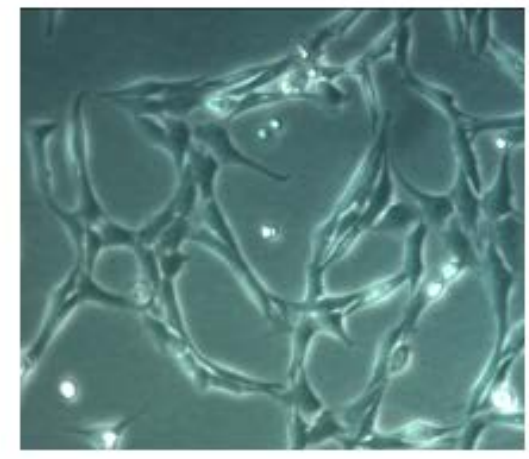

$1321 \mathrm{N1}$

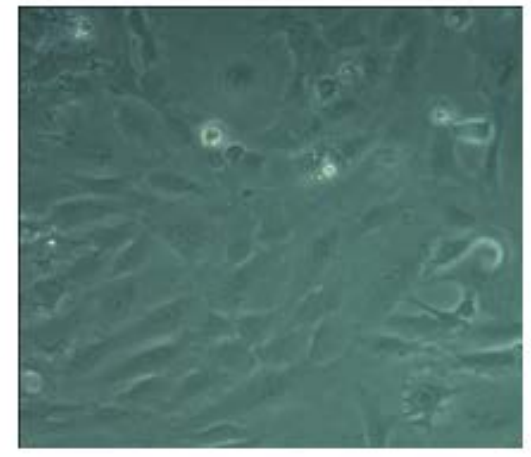

SVGp12 (E)

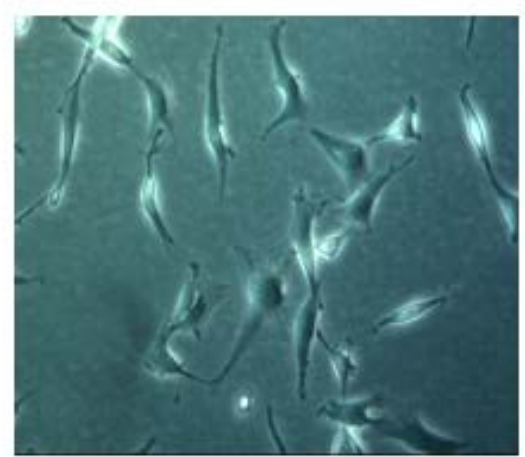

(B)

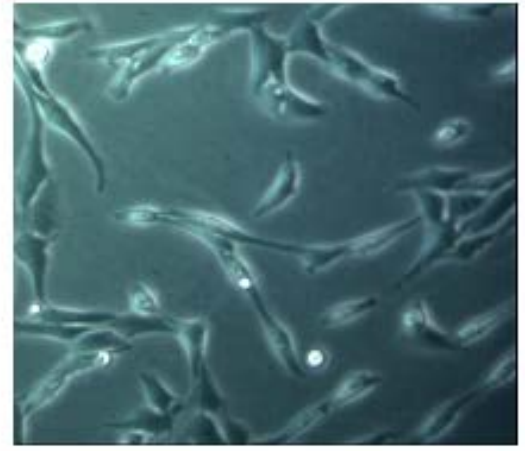

(D)

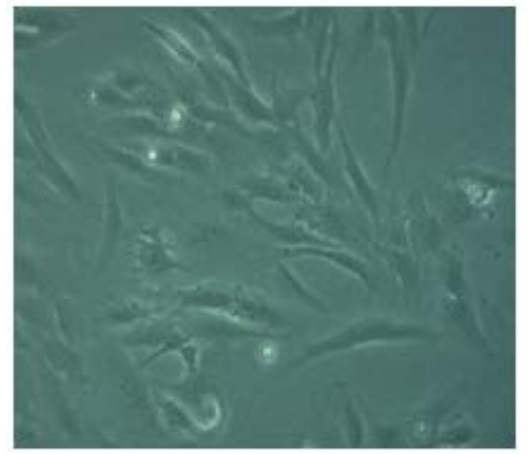

(F)

Figure 2 was adapted from [35] and shows cells of the human glioma cell lines, U87MG (Figure 2A) and 1321N1 (Figure 2C), along with the non-cancerous glial cell line, SVGp12 (Figure $2 \mathrm{E}$ ), that had been cultured in the presence of $C n$-AMP2 at a peptide concentration of $2 \mathrm{mM}$. Also shown are cells of the same cell lines that had been similarly cultured but in the absence of Cn-AMP2 (Figures B, D and F). It can be clearly seen that samples treated with the peptide showed no evidence of cell-death, as indicated by a round morphology; and no sign of cell lysis, as witnessed by membrane fragmentation or the presence of cellular debris. All images are at a $\times 10$ magnification and cell lines were cultured as previously described [35]. 


\section{Figure 3. The passage of $\mathrm{Cn}$-AMP2 across mimics of cancer cell membranes}
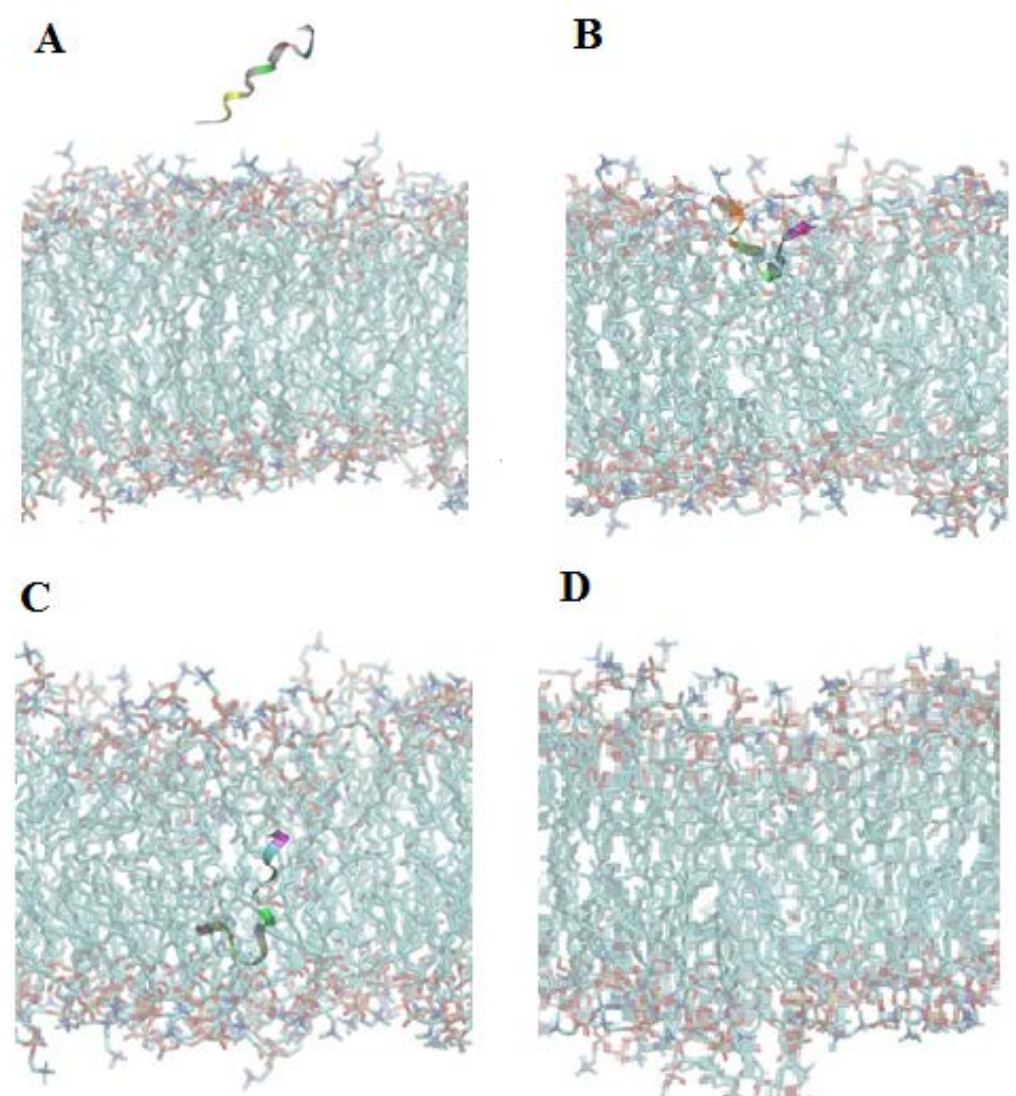

D

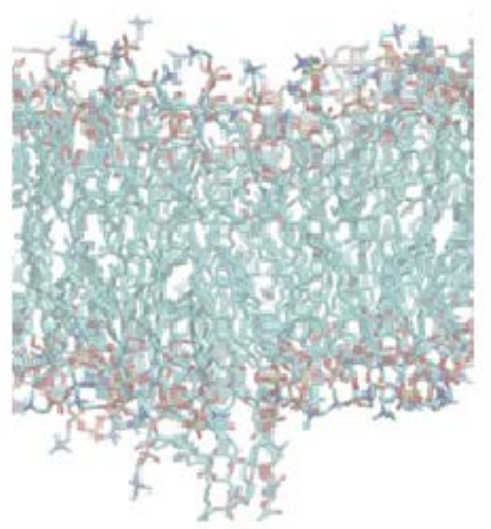

Interaction with intracellular targets that leads to the inhibition of cancer cell proliferation

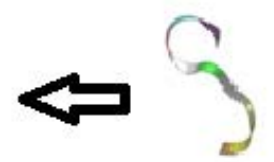
(DNA?)

$\mathbf{E}$

Figure 3 was adapted from [36] and shows molecular dynamic simulations for the interaction of Cn-AMP2 with a model cancer cell membrane. In this simulation, Cn-AMP2 (TESYFVFSVGM [106]) is in an extended conformation and approaches the surface of the membrane (Figure 3A) and inserts (Figure 3B). Insertion of the peptide involves association of its anionic N-terminal segment (TES) with positively charged moieties in the head-group region of the bilayer such as the choline group of DMPC. Complementing these electrostatic interactions, the hydrophobic C-terminal segment of Cn-AMP2 (YFVFSVGM) penetrates the apolar core region of the membrane (Figure $3 \mathrm{~B}$ ). Led by its N-terminal region, the peptide then traverses this core region (Figure 3C) and emerges through the opposing leaflet to migrate away from the membrane surface (Figure 3D) with no significant overall perturbation of the bilayer resulting from the passage of $\mathrm{Cn}$-AMP2 (Figures 3A to 3D). Based on the action of the peptide against the human glioma cell lines, it was suggested that the emergent $C n$-AMP2 attacks 
intracellular targets with the result that the ability of these cells to proliferate is inhibited (Figure 3E).

\section{Figure 4. Structural characteristics of kalata B2 and cycloviolacin Y4}

\section{Kalata B2}

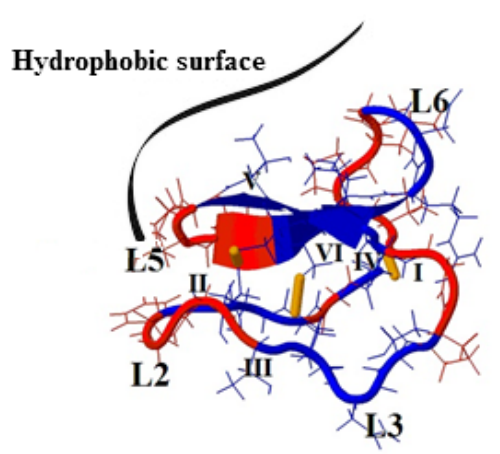

A

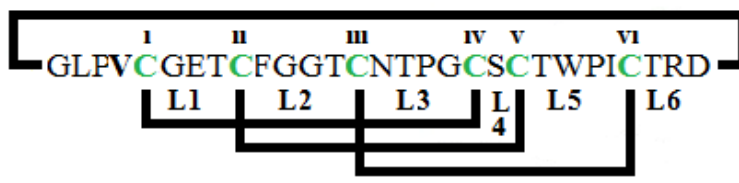

B

\section{Cycloviolacin Y4}

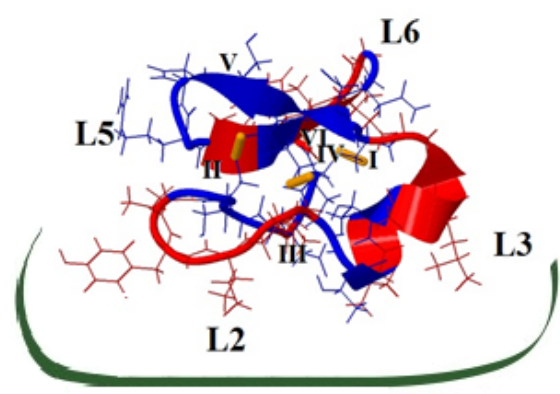

Hydrophobic surface

C

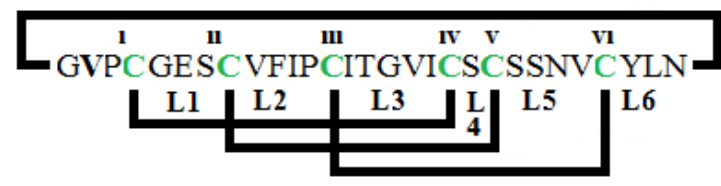

D

Figure 4 was adapted from $[67,80]$ and shows the tertiary structures of kalata B2 (Figure 4A) and cycloviolacin Y4 (Figure 4C), which are Mobius and bracelet cyclotides, respectively. The former group of peptides is distinguished by possession of a cis-proline peptide bond in loop 5. The core of these structures is the 'cysteine knot' motif, which can be seen is formed by conserved cysteine residues, which are indicated as I - VI in Figures 4A and 4C, along with Figures $4 \mathrm{~B}$ and 4D, which shows the primary structures of these peptides. In Figures 4B and $4 \mathrm{D}$, the sequences of the backbone loops between conserved cysteine residues are indicated and annotated as L1 to L6. In Figures 4A and C, it can be seen that these backbone loops define the general surface topology of kalata B2 and cycloviolacin Y4 but for convenience, only some loops are indicated. The topology of these two peptides differs in relation to their hydrophobic surface patches, which are centred on L5 and L6 in kalata B2, and on L2 and L3 in cycloviolacin Y4. In both cases, hydrophobic patches are shown in blue whilst hydrophilic and charged regions are indicated in red. 


\section{Figure 5. The binding of kalata B2 to a PE bilayer}

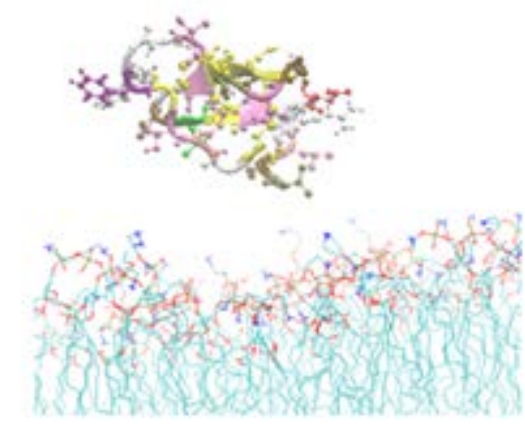

A

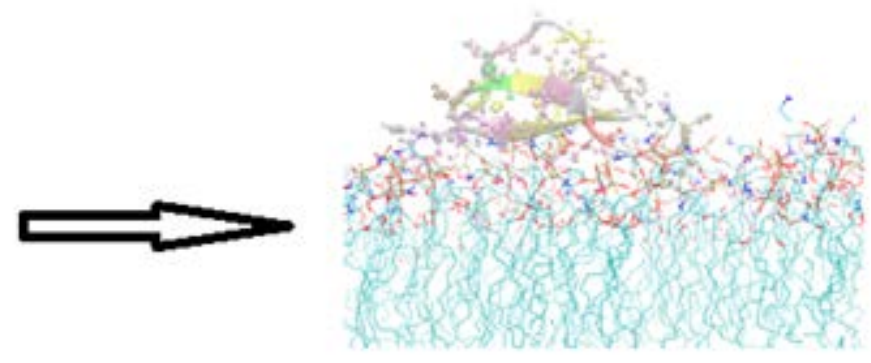

B

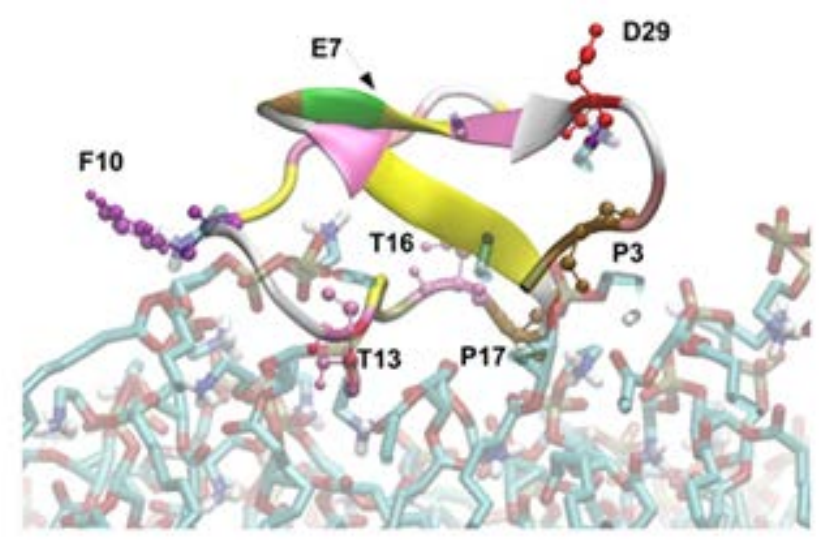

C

Figure 5 shows a molecular dynamic simulation of kalata B2 interacting with a bilayer formed from DMPE. In this simulation, the peptide approaches the membrane surface (Figure 5A) and binds to the lipid-head-group regions with high affinity for these bilayers (Figure 5B), which would support the suggested receptor role for the lipid [62, 81, 82]. Figure 5C shows a close up of PE-bound kalata B2, which predicts that this binding involves electrostatic and hydrogen-bond interactions between ammonium moieties within the head-group region of the bilayer and residues in loops 2 (residues F10 and T13), loop 3 (residues T16 and P17) and loop 6 (residues D29 and P3) of the peptide. These simulations also show that the conserved glutamate residues (E7 in loop 2) of PE-bound kalata B2 is 
Published Harris F, et al 2016 Protein Pept Lett. 2016 May 11. [Epub ahead of print] PMID: 27165406

distal from the membrane surface (Indicated with an arrow in Figure 5C) and is not involved in this binding mechanism, contrasting to previous observations [62, 81, 82].

Figure 6. A model for the membrane interaction of kalata B2

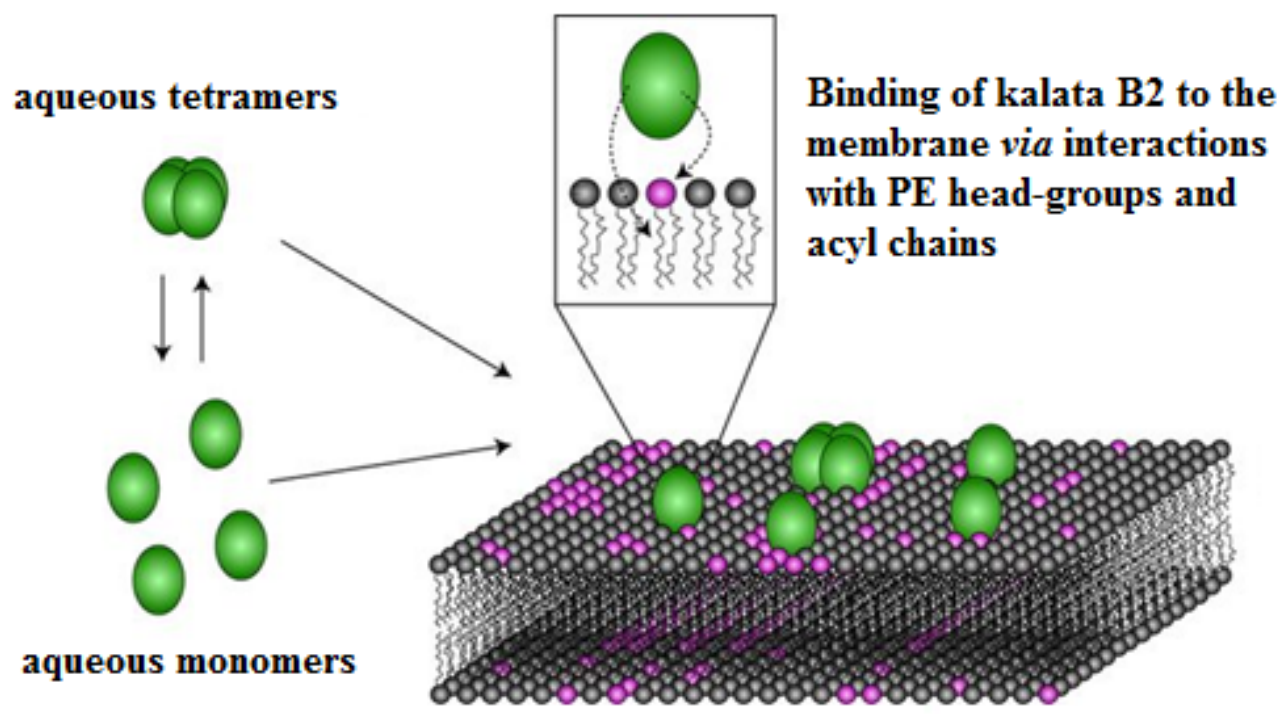

A

B

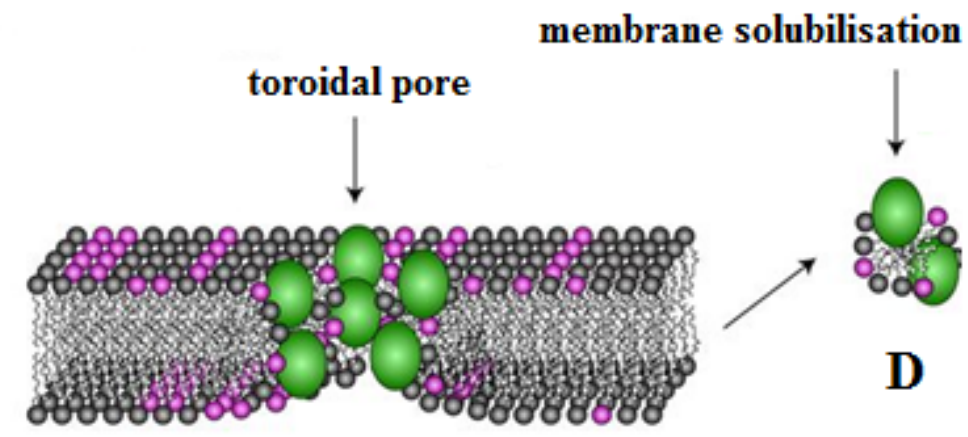

C

Figure 6 was adapted from [82] and shows a model for the membrane interactions of kalata B2 and other ADHPs. According to this model, monomers or oligomers of these cyclotides approach the membrane surface (Figure 6A) and specifically bind PE head-groups whilst interacting non-specifically with the lipid's acyl chains (Figure 6B). The progressive aggregation 
of kalata B2 molecules on the membrane surface, either as monomers or loosely packed oligomers, imposes a positive curvature strain by increasing the distance between membrane lipid head-groups. Once the localized concentration of peptides on the membrane surface reaches a threshold value, they insert into the bilayer whilst remaining in contact with the PE head-group. This action leads to cavitation of the membrane surface and ultimately, the formation of toroidal pores that are lined by lipid head-groups and hydrophilic surfaces of the participating cyclotide molecules (Figure 6C). This process continues until high concentrations of kalata B2 are reached when lipids are extracted from the membrane, which results in solubilisation and ultimately, disintegration of the bilayer (Figure 6D). 